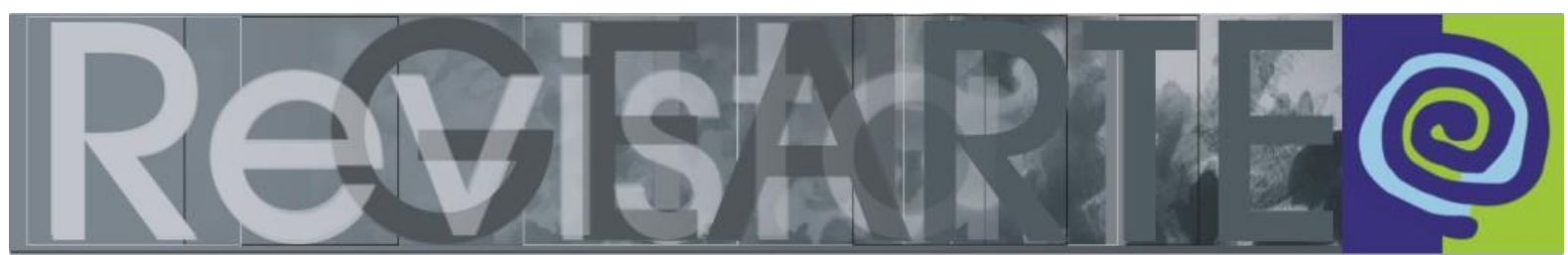

ISSN 2357-9854

\title{
A importância da arte contemporânea para o futuro professor: uma abordagem desde a perspectiva dos estudantes
}

\author{
Mónica Oliveira (Universidade Católica Portuguesa - UCP, Porto, Portugal)
}

\begin{abstract}
RESUMO - A importância da arte contemporânea para o futuro professor: uma abordagem desde a perspectiva dos estudantes - A formação de professores é um processo complexo que deve não só ir ao encontro das necessidades reais dos contextos educativos como também exigir que sejam ouvidos todos os participantes. No entanto, no Ensino Superior a participação de estudantes na construção do desenho curricular é pouco valorizada. Neste estudo, pretendemos analisar o que pensam os estudantes de Licenciaturas em Educação Básica, em Portugal, sobre o contributo da arte contemporânea para a sua formação e para a sua futura profissão. Essa etapa constitui-se determinante pois acreditamos que o processo de ensino-aprendizagem só ganha sentido se os estudantes puderem refletir sobre ele com vista a perspectivar o seu futuro. Trata-se, assim, de uma investigação de natureza quantitativa em que se utilizou o inquérito por questionário. Os resultados evidenciaram que os estudantes valorizaram a arte contemporânea para a sua formação e para o desenvolvimento da sua prática profissional, apontando competências específicas da área.
\end{abstract}

PALAVRAS-CHAVE

Formação inicial de professores. Arte contemporânea. Estudantes

ABSTRACT - The importance of contemporary art to the future teacher: an approach from the perspective of the students - Teacher training is a complex process that must meet the real needs of educational settings and requires that all stakeholders are heard. However in Higher Education, the participation of students in the construction of curriculum design is underrated. In this study we intend to analyze what students in Initial Teacher Training in Portugal think about the contribution of contemporary art to their training and their future profession. This step constitutes decisive because we believe that the teaching-learning process only makes sense if students can reflect on it in order to perspective their future. In this quantitative research we used questionnaires. The results showed that students recognised importance of contemporary art for their training process and for the development of their professional practice pointing specific skills of the area.

KEYWORDS

Initial teacher training. Contemporary art. Students

\section{Introdução}

Este estudo faz parte de uma investigação mais ampla cujo principal objetivo é refletir sobre a importância da arte contemporânea na formação inicial de professores. Assim, pretende ir ao encontro da educação artística tendo por base o mundo e a arte atual e assenta-se na convicção de que a arte contemporânea faculta competências aos estudantes para a sua formação e profissão, uma vez que diz respeito a processos mediante os quais o currículo se torna significativo para os que o recebem (ELLIS, 
2004). A arte contemporânea evidencia-se, atualmente, na nossa sociedade, apresentando um contexto social em que se (re)equacionam valores e conceitos, nos mais diversos campos da vida humana, espelhando diferentes temas que configuram o nosso tempo, estreitando laços entre a vida e o quotidiano das pessoas. Ela comunica e provoca reações e, por isso, torna-se fundamental refletir sobre essas manifestações artísticas, pois cada um de nós é receptor da sua própria cultura, ou seja, é contemporâneo do tempo e da época em que vive e deve confrontar-se com o novo. Como afirma D’Ambrosio, "a preparação do professor para uma nova educação implica viver o novo na sua formação" (2003, p. 64) para que possa inserir-se e influir na sociedade em que está imerso. Esta nova visão de mundo refletida na arte contemporânea é a mesma visão que se exige na formação de professores. Se, como atesta Tedesco ( 2004), a educação hoje está definitivamente ultrapassada e precisa ser reformulada, e o papel do professor deve ser continuamente (re)desenhado (MELLO, 2001), o repensar e operacionalizar uma mudança na formação inicial de professores torna-se inevitável, pois destes cursos sairão os agentes que operarão a transformação na educação básica. Como afirma Tedesco, "um cidadão do século XXI deverá estar formado de tal maneira que seja capaz não só de adaptar-se às mudanças extraordinárias e vertiginosas que estamos vivenciando, mas, sim, de participar das decisões que deverá tomar a sociedade com o intuito de definir o ritmo e as finalidades das mudanças" (2009, p.163) e, para isso, é muito importante a opinião dos diferentes intervenientes educativos: professores, investigadores e estudantes para operar novas práticas educativas.

Tendo em consideração que, num estudo recente, (OLIVEIRA, M., 2015), professores e investigadores (ATKINSON, D.; BALDACHINO J.; AGRA-PARADIÑAS, M.; TRIGO, C.; PALACIOS; HERTH, C;), entre outros, foram já auscultados e assumiram a pertinência deste conceito na formação inicial de professores, parecenos igualmente importante conhecer a perspectiva dos estudantes sobre a pertinência deste conteúdo dada a importância que os estudantes exercem ao transformar o currículo intencionado, em currículo experienciado (ROLDÃO, 1999).

Refletir sobre a formação artística dos futuros professores é pensar nas novas exigências e nos novos desafios; é ir ao encontro das necessidades reais dos 
contextos socioeducativos atuais e propor novos planos de ação, cujo aperfeiçoamento exige que sejam ouvidos todos os intervenientes educativos, nomeadamente os estudantes, que permitam construir e reconstruir opções, expectativas e superar lacunas. Os estudantes têm de ser considerados como agentes das atividades curriculares e, como agentes, desempenham papel significativo na dinamização do conhecimento.

Assim, o conhecimento sobre as concepções que os estudantes têm sobre a arte atual e a sua pertinência para a sua formação, bem como para a sua profissão, tornam-se relevantes na formação inicial de professores. Este estudo pretende analisar as perspectivas dos estudantes e destacar as implicações que podem constituir um contributo para um efetivo conhecimento e alterações curriculares. Neste sentido é que a investigação foi traçada. Das considerações acima descritas, emergem duas questões relacionadas com a complexidade do tema:

Qual a representação que os estudantes têm da arte contemporânea na sua formação?

Os estudantes reconhecem a importância da arte contemporânea para a sua futura profissão?

Estas são algumas perguntas que movem a pesquisa. Ao pretendermos estudar a importância da arte contemporânea na formação inicial e a sua pertinência para o desempenho profissional do futuro professor, não podíamos deixar de refletir sobre dois conceitos que, inevitavelmente, interferem e condicionam a formação e as suas práticas profissionais - o conceito de educação artística, mais concretamente, o de arte contemporânea e a importância dos estudantes na construção do seu curriculum.

\section{A Arte Contemporânea na Formação Inicial de Professores}

Estamos, mais do que nunca, convictos de que sem uma preparação adequada dos futuros professores, a partir da formação inicial, que pressuponha uma (re)significação do que implica o ensino-aprendizagem numa sociedade atual, na área da educação artística, correr-se-á o risco da arte/cultura não ter qualquer expressão 
e consequência educativa em termos da melhoria da qualidade da educação. Para que isso não venha a acontecer na área artística, a formação dos professores não poderá restringir-se à preparação dos estudantes para um uso instrumental da arte que, aliás, tem sido essencialmente a marca da formação de professores nas últimas décadas. A educação "deve dar conta das transformações que experimenta o contexto cultural imediato em que se desenvolvem as tarefas formativas, ou seja, o contexto de sentidos e significados que permite que os sistemas educacionais funcionem como meio de transmissão e integração culturais" (TEDESCO, 2004, p. 34). É necessário repensar as práticas educativas e perceber que tipo de profissional está sendo formado nestes cursos assim como pensar um currículo à luz da pedagogia crítica e das recentes manifestações artísticas que povoam o nosso quotidiano e a que nós apelidamos de arte contemporânea. A formação artística, enquanto área do saber, deverá incluir discussões teóricas, sobre paradigmas de educação artística, que torne contemporânea a educação oferecida aos estudantes sustentada por bases conceituais que assegurem uma educação artística de forma que não reste ao professor uma técnica sem competência (LELIS, 2001). Esta formação deve ir ao encontro de desenvolver, nomeadamente, habilidades e competências para a vida, proporcionando formas de pensar plurais, estimulando a percepção, a coordenação motora, a capacidade de tomar decisões de forma autônoma e crítica, estimulando a sensibilidade estética e o pensamento inovador.

E todos estes requisitos estão presentes na arte contemporânea. Quando falamos nela, estamos nos referindo a um conjunto de manifestações artísticas, que se constitui numa linguagem visual que está acontecendo perante nossos olhos e não podemos negar. Ela comunica temas que informam a sociedade atual. Não apresenta fronteiras entre diferentes vertentes artísticas, desafiando a hegemonia das linguagens tradicionais como a pintura, escultura ou desenho. Mais do que afirmar e confirmar teses, ela está muito mais preocupada em desafiar, em levantar hipóteses, em nos provocar e isso nos desassossega. A arte contemporânea é como afirma Cauquelin, "a arte do agora, a arte que se manifesta no mesmo momento e no próprio momento em que o público a percebe" (CAUQUELIN, s/d, p. 6). Ela explora a percepção e a ação imaginativa do espectador, propondo múltiplas possibilidades de leitura dos seus atos e produções, convidando-o a ser um participante ativo nesse 
diálogo. $\mathrm{O}$ interesse da arte contemporânea reside em construir um caminho de conhecimentos novo, que não tenha sido explorado.

Desta forma, acreditamos que a arte contemporânea na formação inicial de professores:

- visa a recepção e produção das imagens que nos rodeiam através de diferentes linguagens artísticas, ou seja, a utilização da arte contemporânea como elemento ativo da vida quotidiana do estudante, como algo próximo da sua realidade, permitindo ir ao encontro da construção da sua identidade;

- orienta para a transformação, para a mudança, para a inovação e para a adaptação ao contexto atual;

- desafia e inquieta a própria forma de ver, pensar e trabalhar a própria arte;

- $\quad$ potencializa a educação humana do sujeito social autônomo e inventivo;

- fomenta a aquisição de consciência crítica, criativa, participativa e questionadora;

- assegura o domínio dos conteúdos e a compreensão dos princípios básicos que fundamentam o ensino numa visão globalizada da cultura;

- articula aspectos teóricos e práticos com a finalidade de construir uma ponte coerente e consistente entre o que os estudantes aprendem e o que se espera que, posteriormente, desenvolvam como profissionais;

- permite ao estudante ser um agente ativo, criador do seu percurso e não um simples interlocutor passivo a quem se debita informação;

- pressupõe uma intencionalidade pedagógica orientada no sentido da compreensão do conhecimento específico e da sua relação com outros conhecimentos;

- implica um conhecimento artístico que não é a adoção de um modelo pedagógico uno e intocável, mas sim uma orientação formativa que permita aos estudantes construírem o seu próprio corpo de conhecimentos.

\section{A importância dos alunos no (re)desenhar planos curriculares}

As questões curriculares são geralmente discutidas, nomeadamente, entre professores, investigadores e equipes do Ministério. A importância de auscultar os estudantes passa por considerar que estes fazem parte da comunidade acadêmica e são os elementos, seguramente mais "visados", quando se trata de falar de reformas 
educativas. Por essa razão, buscamos traçar um quadro das valorizações que os estudantes fazem quanto à questão da formação e à sua contribuição para o desempenho profissional. É importante conhecer em profundidade aquilo que o estudante pensa sobre o ensino-aprendizagem e o que dela espera, bem como as suas aspirações, os seus códigos e os seus valores de referência, e, posteriormente, considerar estes dados como básicos na elaboração das reformas dos sistemas educativos. A formação de um estudante no ensino superior é decisiva para a vida pessoal de cada um, quer no que concerne à aquisição de competências para a sua atividade profissional, quer para o acesso à cultura e ainda para o exercício da cidadania. Daí que os estudantes devem ser os protagonistas ativos na procura de novos caminhos trilhados durante o seu processo de formação.

Os estudantes não são sujeitos passivos, nem possuem apenas capacidade para responder às exigências do ensino-aprendizagem de acordo com o que está normalizado como comportamento adequado. Do estudante do ensino superior espera-se comprometimento crítico, dinamismo e responsabilidade em relação à sua aprendizagem. Os estudantes, ao longo do seu curso, refletem sobre as concepções e as práticas em relação a questões curriculares fundamentais (o que ensinar e para quê, que estratégias utilizar, como as operacionalizar) e consideram também a questão relacionada com a empregabilidade, uma vez que o mercado de trabalho exige cada vez mais pessoas capazes de inovar e pensar de forma crítica e criativa. Um exemplo claro sobre a importância e reconhecimento da arte na educação, foi a declaração de Arne Duncan, Secretário de Educação do Governo Americano:

Education in the arts is more important than ever. In the global economy, creativity is essential. Today's workers need more than just skills and knowledge to be productive and innovative participants in the workforce. Just look at the inventors of the iPhone and the developers of Google: they are innovative as well as intelligent. Through their combination of knowledge and creativity, they have transformed the way we communicate, socialize, and do business. Creative experiences are part of the daily work life of engineers, business managers, and hundreds of other professionals. To succeed today and in the future, America's children will need to be inventive, resourceful, and imaginative. The best way to foster that creativity is through arts education. (DUNCAN, 2011, p.1)

Perceber a perspectiva dos estudantes sobre a aprendizagem da arte contemporânea na sua formação pode contribuir para compreender as suas 
expectativas em relação aos conteúdos, às competências e às práticas pedagógicas na área da educação artística no mundo atual e para entender de que forma este conteúdo pode influenciar o seu perfil profissional. Além disso, esta auscultação recolheu dados que possuem uma significativa influência na relação entre professoraluno, aluno-conhecimento, conhecimento-profissionalização e profissionalizaçãoexercício profissional. Por essa razão, os estudantes devem ser vistos como co construtores das propostas pedagógicas no ensino-aprendizagem, capazes de se posicionarem sobre aspectos de sua formação e buscar esse olhar parece-nos necessário. Só desta forma será possível a implementação de novas reformas educativas com algum sucesso.

\section{Metodologia}

Considerando as perguntas que traçamos para nortear este projeto de investigação, que pretendiam perceber quais as representações que os estudantes tinham sobre a importância da arte contemporânea na sua formação e na sua futura profissão, torna-se claro que pretendíamos realizar uma pesquisa educacional com o intuito de explicar fenômenos e contribuir para desenvolver alguns fundamentos teóricos. Para tal, optamos por realizar uma investigação de natureza quantitativa. A técnica de coleta de dados utilizada foi o inquérito por questionário.

\section{Estrutura do questionário}

A aplicação deste questionário contribuiu para elucidar as indagações construídas na problemática dessa investigação. O questionário utilizado foi do tipo aberto, o qual proporciona respostas de maior profundidade, ou seja, dá ao sujeito maior liberdade de resposta, podendo esta ser redigida pelo próprio.

Estruturou-se o questionário de maneira a identificarem-se as categorias e os seus objetivos como contribuição para responder às problemáticas da investigação, conforme Quadro 1. 
Quadro 1- Categorização e objetivos específicos do questionário

\begin{tabular}{|c|c|}
\hline Categorias & Objetivos específicos \\
\hline $\begin{array}{l}\text { Conhecimentos sobre arte/arte } \\
\text { contemporânea. }\end{array}$ & $\begin{array}{l}\text { Inventariar os conhecimentos dos estudantes sobre } \\
\text { arte/arte contemporânea. }\end{array}$ \\
\hline $\begin{array}{l}\text { Importância da arte contemporânea na } \\
\text { formação de professores. }\end{array}$ & $\begin{array}{l}\text { Analisar o grau de valorização da arte contemporânea } \\
\text { pelos estudantes para a sua formação. }\end{array}$ \\
\hline $\begin{array}{l}\text { Pertinência da operacionalização da } \\
\text { arte contemporânea na educação. }\end{array}$ & $\begin{array}{l}\text { Constatar como os estudantes percebem a importância da } \\
\text { arte contemporânea na Educação. }\end{array}$ \\
\hline $\begin{array}{l}\text { Tipologia de atividades a desenvolver } \\
\text { com crianças tendo por base a arte } \\
\text { contemporânea. }\end{array}$ & $\begin{array}{l}\text { Interpretar o nível de preparação dos estudantes em } \\
\text { relação à arte contemporânea para atuar no terreno da } \\
\text { educação após conclusão do curso. }\end{array}$ \\
\hline
\end{tabular}

\section{Caracterização da população e amostra}

A amostra é composta por 350 estudantes de Licenciaturas em Educação Básica, de oito Escolas Superiores de Educação de Portugal nas quais a arte contemporânea é um conteúdo abordado durante o curso. Da amostra recolhida, 80\% das instituições são de Ensino Superior Público e $20 \%$ de Ensino Superior Particular. A maioria dos estudantes (280) era do sexo feminino e as idades oscilaram entre 23 e 25 anos. Já do sexo masculino, apenas contamos com 20 alunos cujas idades se situavam no intervalo entre os 24 e 26 anos. Todos os estudantes estavam matriculados no último ano do mestrado em Formação de Professores, 30\% na especialização em Educação Pré-escolar e $70 \%$ na especialização em Ensino do 1..ำ Ciclo do Ensino Básico.

\section{Aplicação do questionário}

No final do curso de mestrado foi solicitado aos estudantes o preenchimento de um questionário. A aplicação do questionário realizou-se de forma anônima, garantindo assim a confidencialidade das suas respostas (LIMA, 2006). Dos 500 questionários entregues para preenchimento aos estudantes, apenas 350 foram devolvidos. Após a recolha dos questionários, procedeu-se à análise de conteúdo das 
respostas dadas através de um processo de categorização emergente (BARDIN, 1995).

\section{Análise e discussão dos dados}

\section{Interesse em ver arte}

Do total do sujeitos, $75 \%$ dos estudantes responderam que gostam de ver arte: $20 \%$ dos quais afirmaram que a arte os fascina com a sua criatividade; $15 \%$ responderam que a arte os interpela e lhes provoca vários sentimentos; $12 \%$ justificaram o seu interesse pela arte na medida em que esta mostra várias formas de ver o mundo; $10 \%$ sustentaram o seu interesse em conhecer diferentes obras e artistas; já $8 \%$ responderam que gostam de ver arte embora não visitem muitos espaços de arte pelo custo financeiro que implica, mas recorrem à internet; 5\% responderam que o gosto que têm em ver arte advém de uma experiência continuada em visitarem diferentes espaços de arte desde crianças; e $5 \%$ gostam de arte porque a entendem desafiadora na interpretação dos seus significados.

Não gostar de ver arte foi uma afirmação de $25 \%$ dos inquiridos: $12 \%$ dos estudantes, embora não gostem de ver arte, reconhecem a sua importância na medida em que a consideram essencial para a construção pessoal e cultural do ser humano; $8 \%$ afirmam que nunca tiveram interesse pela arte; e $5 \%$ justificam a sua falta de interesse por não a entenderem.

\section{0 que aprendeu com a Educação Artística na Formação Inicial}

Todos os estudantes afirmam ter adquirido conhecimentos que concorrem para o mesmo objetivo - o seu perfil profissional - a prática profissional e a sua formação.

No que diz respeito ao primeiro aspecto - a prática profissional - 31,6\% dos estudantes afirmam que aprenderam formas diversificadas de propor atividades, técnicas e materiais a partir da arte e dos artistas; $23,3 \%$ referem que aprenderam a utilizar a arte contemporânea com um conteúdo pedagógico; e 11,4\% dos estudantes afirmam que aprenderam a conceder à arte mais importância pedagógica. 
Já relacionado com o segundo aspecto, surgem 15,8\% que afirmam ter conhecido novos artistas e processos de criação diversos; 9,5\% assumem ter aprendido o que se entende por arte contemporânea; $8,4 \%$ salientam que a sua aprendizagem recaiu no desenvolvimento da criatividade.

\section{A importância de conhecimentos sobre arte contemporânea}

llação positiva a retirar é o fato de ser uma amostra em que, majoritariamente, os inquiridos consideram importante possuir conhecimentos sobre arte contemporânea $(73,3 \%)$ e somente $26,7 \%$ dizem não considerar importante possuir conhecimentos sobre arte contemporânea justificando a sua resposta com o fato de não saberem o que se entende por arte contemporânea.

No que concerne às respostas afirmativas, $38,3 \%$ dos inquiridos justificam a sua posição pelo fato de a arte contemporânea contribuir para a cultura geral de um professor; 8,3\% com o fato de ser a forma artística mais atual; e 8,3\% explicam que permite a aquisição de conhecimento sobre a realidade atual. Para além das justificativas acima apresentadas, 6,7\% dos estudantes afirmam a importância da arte contemporânea pela sua integração no currículo e $5 \%$ entendem que devem ter conhecimentos sobre arte contemporânea, pois devem diversificar os seus conhecimentos no campo artístico. Há que se referir ainda, que $6,7 \%$ dos inquiridos consideram necessário ter conhecimentos sobre a arte contemporânea mas não justificaram a sua resposta.

\section{Conhecimento sobre artistas plásticos contemporâneos e sua justificativa}

Neste ponto do questionário pediu-se aos estudantes que enumerassem três artistas plásticos contemporâneos.

O nome da artista Joana Vasconcelos foi referenciado por $44 \%$ dos estudantes que justificaram o seu conhecimento por ser uma figura midiática $(20 \%)$, pela diversidade de material que utiliza do nosso quotidiano $(23 \%)$ e por retratar a tradição portuguesa (1\%). Paula Rego foi mencionada por $4 \%$ que justificaram o seu interesse pela representação do simbólico; João Vieira foi apontado por $4 \%$ dos inquiridos por trabalhar com o alfabeto; e 3\% salientam o nome da artista Ana Vidigal por usar 
personagens do seu imaginário infantil. As justificativas mencionadas surgem muito associadas a temáticas a serem trabalhadas com as crianças. Ainda foram mencionados artistas como Marc Jenkins pela mensagem visual (1\%) e vários artistas do século XX: Jackson Pollock pela sua vida (1\%); Miró pela sua expressão artística inigualável (1\%); Frida Khalo por representar a mulher (1\%); Gaudí pela sua forma de expressão única (1\%); Van Gogh (1\%) e Picasso (1\%) sem justificativa.

Ainda, 1\% respondeu que, embora conhecessem alguns artistas, não se recordavam dos seus nomes. Por fim, 29\% responderam não conhecer artistas contemporâneos.

\section{Pertinência da arte contemporânea na Educação Básica}

Nesta questão verificamos que $75 \%$ dos inquiridos concordam com a necessidade dos seus futuros alunos desenvolverem trabalhos relacionados com arte contemporânea enumerando algumas razões: $24 \%$ dos estudantes consideram que esse tipo de arte promove a criatividade; $22 \%$ entendem que este tipo de arte desenvolve o gosto por diferentes formas artísticas e permite a aquisição de novos conhecimentos sobre a especificidade desta área; $8 \%$ referem que a arte contemporânea permite 0 acesso a vários tipos de arte; $6 \%$ consideram que desenvolve o espírito crítico e outros $6 \%$ acham que se aprendem novas técnicas e materiais; $5 \%$ veem neste tipo de arte uma forma de conhecer melhor o mundo em que vivemos; e $4 \%$ partilham da ideia de que a arte contemporânea ajuda a desenvolver outras áreas de conteúdo.

Também 25\% dos estudantes não consideram pertinente propor atividades relacionadas com arte contemporânea aos seus futuros alunos: $20 \%$ dos inquiridos responderam não saber se os alunos deveriam desenvolver trabalhos relacionados com arte contemporânea justificando não ter conhecimentos sobre este assunto; e 5\% dos inquiridos entendem que os alunos não devem trabalhar a arte contemporânea mas não apresentaram justificativa. 


\section{Tipologia de atividades a serem propostas aos alunos de Educação Básica relacionadas com arte contemporânea}

Destaca-se que $25 \%$ dos estudantes não proporiam atividades relacionadas com arte contemporânea aos seus futuros alunos, uma vez que não têm conhecimentos sobre arte contemporânea. Todavia, dos inquiridos que o fariam, (75\%), 40\% utilizariam diferentes técnicas de modo a desenvolver a criatividade nas crianças, 20\% realizariam atividades relacionadas com artistas plásticos e 15\% efetuariam visitas a museus de arte contemporânea para que as crianças pudessem desenvolver o gosto pela arte.

\section{Considerações finais}

A título de conclusão, impõe-se, pois, realçar alguns dos aspectos que nos parecem relevantes e que, mais do que meras conclusões, se configuram como linhas de força que nortearam este percurso investigativo e que esperamos ajudem a (re)estruturar e/ou modificar o nosso pensamento pedagógico, enquanto professores. Assim e indo ao encontro da resposta às duas questões que direcionaram esta investigação, destacam-se os seguintes aspectos:

Interesse por arte: pese que, embora a maioria dos estudantes goste de ver arte e considere importante ter conhecimentos sobre arte contemporânea para a sua futura profissão, apresentam uma escassez de conhecimentos sobre artistas plásticos da atualidade e equívocos sobre o que se entende por arte contemporânea apresentando artistas do século XX como contemporâneos. Por outro lado, é importante também salientar que um número significativo de estudantes afirma desconhecer a arte contemporânea.

Competências relacionadas com a sua formação: os estudantes salientaram a aquisição de novos conhecimentos na área, quer relacionados com artistas, obras e com o conceito que subjaz a este tipo de arte, quer relacionados com a educação artística através da conceptualização de atividades e sua planificação. Também o desenvolvimento da criatividade, da autonomia no processo artístico-pedagógico e do espírito crítico foram, de forma geral, mencionados. 
Relação entre a formação e a sua prática profissional: as respostas aos inquéritos evidenciaram uma preocupação dos estudantes com as suas aprendizagens e o seu futuro enquanto professores, percebendo a pertinência e o potencial pedagógico da arte contemporânea na educação como sendo um documento que espelha a sociedade atual, próximo das vivências das crianças. Mencionaram também a tipologia de atividades diversificada e as possibilidades interdisciplinares desta área.

Majoritariamente os estudantes consideram que as crianças devem desenvolver trabalhos relacionados com arte contemporânea na escola e proporiam atividades relacionadas com diferentes técnicas, com artistas plásticos, com visitas a museus de arte em virtude de verem neste tipo de arte possibilidades pedagógicas que ajudam o desenvolvimento global dos alunos, valorizando, sobretudo, o desenvolvimento da criatividade, o gosto pela arte e o desenvolvimento do espírito crítico.

Os aspectos suprarreferidos permitem afirmar que os estudantes consideram, na sua maioria, que a arte contemporânea concorre para o seu perfil profissional. Para isso muito contribuíram os conhecimentos adquiridos na sua formação e uma nova postura na forma de estar e ver a arte contemporânea. O alargar de horizontes dos estudantes, abrindo-Ihes as portas ao entendimento da arte contemporânea e da sua aplicabilidade prática no processo educativo, é uma garantia de que as novas gerações terão a possibilidade de serem confrontadas com a arte desde o início das suas vidas, abrindo assim a arte contemporânea a novos públicos e, principalmente, a públicos mais informados ou, pelo menos, com mais perspectivas.

\section{Referências}

BARDIN, Laurence. Análise de conteúdo. Lisboa: Persona, 1995.

D'AMBROSIO, Ubiratan. Novos paradigmas de atuação e formação de docente. In: PORTO, Tania (Org,). Redes em construção; meios de comunicação e práticas educativas. Araraquara: Junqueira e Marin, 2003. p.55-77.

CAUQUELIN, Anne. A arte contemporânea. Portugal: Editora Rès, s/d.

DUNCAN, Arne. Reinvesting in arts education: winning America's future through creative schools. Washington: Knight Foundation, 2011.

ELLIS, Arthur. Exemplars of curriculum theory. Larchmont, NY: Eye on Education, 2004. 
LELIS, Isabel. Do ensino de conteúdos aos saberes do professor: mudança de idioma pedagógico?, Educação \& Sociedade, Campinas, v. 22, n. 74, p. 43-58. 2001.

LIMA, Maria. Percepção de riscos e desigualdades sociais. In: PINTO, José; BORGES, Virgílio (Eds.). Desigualdades, desregulação e riscos nas sociedades modernas. Porto: Edições Afrontamento, 2006. p.267-290.

MELLO, Guiomar Namo (2001). Resignificación del rol de los docentes: algunas contribuciones. Disponível em: http://documents.tips/download/link/03-resignificacion-del-rol-docente. Acesso em: 17 fev. 2016.

OLIVEIRA, Mónica. A arte contemporânea para uma pedagogia crítica na formação inicial de professores. Porto: Associação de Professores de Expressão e Comunicação Visual, 2015.

ROLDÃO, Maria. Os professores e a gestão do currículo: perspectivas e práticas em análise. Porto: Porto Editora, 1999.

TEDESCO, Juan. Formação científica para todos. In: WERTHEIN, Jorge; CUNHA, Célio (Orgs.). Ensino de ciências e desenvolvimento: o que pensam os cientistas. São Paulo: Instituto Sangari, 2009. p. 161171.

TEDESCO, Juan. Educação e novas tecnologias. São Paulo: Editora Cortez, 2004.

\section{Mónica Oliveira}

Pós-doutora em Didática das Expressões Artísticas pela Faculdade de Belas Artes da Universidade do Porto. Doutora em Artes Plásticas pela Faculdade de Belas Artes da Universidade de Salamanca, 2000. Professora Coordenadora na Escola Superior de Educação de Paula Frassinetti, desde 1996. Investigadora integrada do Centro de Estudos em Desenvolvimento Humano da Universidade Católica Portuguesa do Porto. Investigadora colaboradora do Instituto de Investigação em Arte, Design e Sociedade - Núcleo de Educação Artística da Faculdade de Belas Artes da Universidade do Porto. Autora de várias publicações na área da Educação Artística, llustração e Artes Plásticas. Foi membro das Comissões de Especialistas na área da Formação de Professores Ministério da Ciência e Ensino Superior.

Email: monica@esepf.pt

Currículo: http://www.degois.pt/visualizador/curriculum.jsp?key=4440822994858991

Recebido em 20 de março de 2016 Aceito em 15 de abril de 2016 